\title{
Hypercalcaemic crisis due to parathyroid adenoma of atypical location
}

\author{
Maria M. Kościuszko ${ }^{\circledR 1}$, Agnieszka Adamska ${ }^{\circledR 1}$, Anna Popławska-Kita ${ }^{\circledR 1}$, Katarzyna Siewko ${ }^{\circledR 1}$, \\ Alicja Rydzewska-Rosołowska ${ }^{\circledR 2}$, Janusz Myśliwiec ${ }^{\circledR 3}{ }^{3}$, Piotr Myśliwiec ${ }^{\circledR 4}$, Mirosław Kozłowski ${ }^{\circledR 5}$, \\ Adam Krętowski ${ }^{1}$
}

${ }^{1}$ Department of Endocrinology, Diabetology, and Internal Medicine, Medical University of Bialystok, Bialystok, Poland ${ }^{2} 2^{\text {nd }}$ Department of Nephrology and Hypertension with Dialysis Unit, Medical University of Bialystok, Bialystok, Poland ${ }^{3}$ Department of Nuclear Medicine, Medical University of Bialystok, Bialystok, Poland ${ }^{4}$ Department of General and Endocrine Surgery, Medical University of Bialystok, Poland

${ }^{5}$ Department of Thoracic Surgery, Medical University of Bialystok, Poland

Key words: hypercalcaemia; hyperparathyroidism; renal dialysis

A 40-year-old patient was hospitalized due to a fourth episode of renal "colic" attack. On admission the patient was conscious with slow verbal contact, sleepy, hypotensive (80/60 mmHg), tachycardic (110 beats/min) complaining of nausea accompanied with abdomenal pain and signs of significant dehydration. Laboratory tests performed showed normocytic anaemia $(\mathrm{Hb}=9.1 \mathrm{~g} / \mathrm{dL})$, elevated levels of inflammatory markers (CRP $=190 \mathrm{mg} / \mathrm{L})$, urea $(70.62$ $\mathrm{g} / \mathrm{dL})$, creatinine $(2.62 \mathrm{mg} / \mathrm{dL})$ and PTH (156.4 pmol/L) in blood serum, hypercalcaemia $(5.0 \mathrm{mmol} / \mathrm{L})$ with hypophosphataemia $(0.63 \mathrm{mmol} / \mathrm{L})$, normocalciuria with hypophosphaturia, vitamin D deficiency $(23.0 \mathrm{ng} / \mathrm{dL})$, and hypomagnesaemia $(0.7 \mathrm{mmol} / \mathrm{L})$. In the ultrasound of the thyroid gland hypoechogenic lesions were found, which corresponded to a lower right parathyroid adenoma with size $30 \times 15 \times 10 \mathrm{~mm}$. An aspiration fine-needle biopsy with PTH determination from the washed needle was performed, and an undetectable PTH value was observed ( $<0.3 \mathrm{pmol} / \mathrm{L}$ ). In a scintigraphy study using MIBI-99-Tc and in the SPECT/CT images of the neck, a radiotracer corresponding to the lower right parathyroid adenoma of the size of $31 \mathrm{~mm}$ was found in the mediastinal region (Fig. 1). Initially, parenteral hydration was used for treatment, with furosemide, bisphosphonate, and cinacalcet, but persistent hypercalcaemia $(\mathrm{Ca}=4.77 \mathrm{mmol} / \mathrm{L})$ was observed. In the absence of clinical and biochemical improvement, after 48 hours of conservative therapy a haemodialysis session was scheduled with a temporary reduction in calcium $(\mathrm{Ca}=2.99 \mathrm{mmol} / \mathrm{L})$, but it was complicated with thrombosis of the right internal jugular vein. The patient was qualified for urgent parathyroidectomy. However, persistent hypercalcaemia $(\mathrm{Ca}=3.64 \mathrm{mmol} / \mathrm{L})$, hypo-
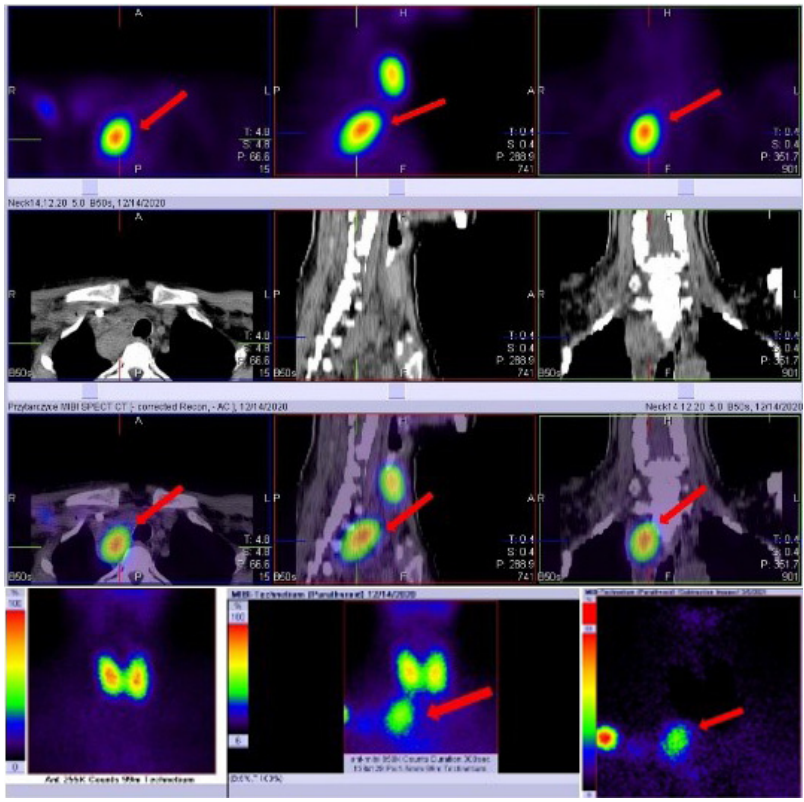

Figure 1. MIBI-99-Tc scintigraphy before and after subtraction of images (MIBI-99mTc minus 99mTc), SPECT/CT images of the neck and MIBI-99mTc planar imaging plus early phase SPECT/CT imaging before first operation shows irregular strokes of $31 \mathrm{~mm}$ accumulating a radiotracer corresponding to the lower right parathyroid adenoma (arrows)

phosphataemia $(\mathrm{p}=0.67 \mathrm{mmol} / \mathrm{L})$, and high PTH $(175.8$ $\mathrm{pmol} / \mathrm{L}$ ) were observed after surgery. Due to suspected non-radical parathyroidectomy, control parathyroid scintigraphy exposed the area of increased accumulation of radiotracer located in the right upper mediastinal area, just behind the trachea (Fig. 2). In thoracic CT scans, a solid tuberous mass of $28 \times 32 \times 50 \mathrm{~mm}$, probably 


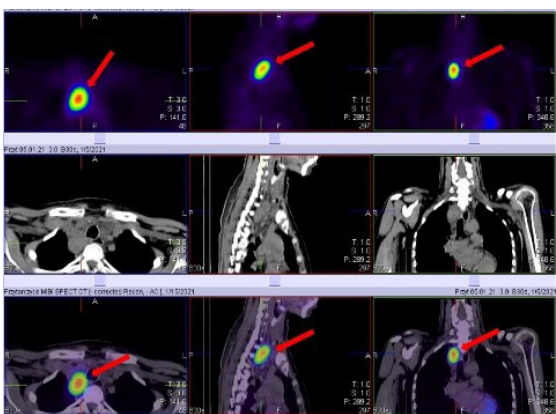

Figure 2. MIBI-99 scintigraphy before and after subtraction of images (MIBI-99mTc minus 99mTc), SPECT/CT images of the neck and MIBI-99mTc planar imaging plus early phase SPECT/CT imaging after first operation shows exposed area of increased accumulation of radiotracer located in the right upper mediastinal area, just behind the trachea - lower right parathyroid adenoma (arrows)

a parathyroid adenoma, was shown (Fig. 3). The patient was re-qualified for parathyroidectomy by the thoracic surgeons. In the early postoperative period, high calcium levels (Ca $\left.=5.14 \mathrm{mmol} / \mathrm{L}, \mathrm{Ca}^{2+}=1.83 \mathrm{mmol} / \mathrm{L}\right), \mathrm{PTH}(198.9$ $\mathrm{pmol} / \mathrm{L})$, and hypophosphataemia $(\mathrm{p}=0.63 \mathrm{mmol} / \mathrm{L})$ were again observed. The patient was planned for surgery again — right-sided video thoracoscopy (VATS) — and the mediastinal tumour was finally removed (intraoperative histopathological result - parathyroid adenoma), and intraoperative reduction in PTH concentration 15 minutes after removal of the lesion $(\mathrm{PTH}=22.9 \mathrm{pmol} / \mathrm{L})$ was obtained. Unfortunately, surgery was complicated by a large haematoma of the right pleura. Histopathological examination of the lesion removed during surgery revealed a parathyroid adenoma (synaptophysin S100[-], Ki67[+], in $2 \%$ of panCK[+] TTF1[-] cells). Further therapy, due to the observed gradual decrease in calcium levels, low concentration of PTH $(<0.3 \mathrm{pmol} / \mathrm{L})$ and the associated risk of developing hungry bone syndrome (HBS), and substitution with parenteral and oral calcium preparations and alphacalcidol was initiated. Gradual normalization of calcium was observed, and the patient was discharged from hospital with the recommendation of continuing oral administration of calcium and alphacalcidol.

Primary hyperparathyroidism is most often subclinical, and diagnosis is determined during laboratory screening [1-2]. Life-threatening hypercalcaemic crisis is more often observed with ectopic localization of parathyroid adenoma (16\%) [1]. Most often, ectopia affects the parathyroid glands located in the upper and posterior mediastinum (62\%) [1]. Therapeutic treatment of hypercalcaemia is multidirectional and should prepare for the surgical removal of parathyroid adenoma. A very important element in surgical treatment is accurate preoperative imaging. Common methods of imaging are ultrasound of the neck area, computed tomography $(\mathrm{CT})$, and magnetic resonance imaging (MRI). Scin-

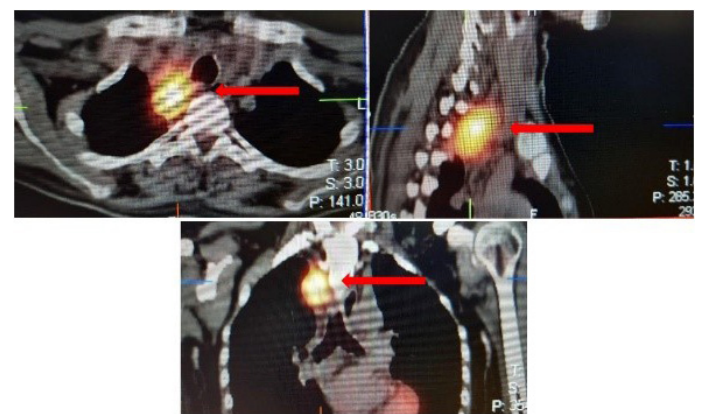

Figure 3. Thoracic computed tomography shows a solid tuberous mass of $28 \times 32 \times 50 \mathrm{~mm}(\mathrm{LR} \times A P \times H F)$ not uniformly strengthening after contrast administration, probably a parathyroid adenoma (arrows)

tigraphy with MIBI-Tc99m (methoxyisobutylisonitrile TechNet) has its special place in the imaging diagnostics of PHPT. In the case of its insufficiency 18F-choline PET/CT or ${ }^{11} \mathrm{C}$-methionine PET/CT scintigraphy may be used [8]. The sensitivity of the above methods in the localization of parathyroid adenoma is $60-100 \%$ and 80-100\%, respectively [3].

In the case of ectopic mediastinal localization of parathyroid adenoma, surgery can be carried out with access through the neck, through the middle sternotomy, or VATS. After successful surgery, the expected reduction in calcium levels usually occurs within 2-4 days [4]. Risk factors for HBS are age ( $>65$ years old), high preoperative calcium levels (> $3.5 \mathrm{mmol} / \mathrm{L}), \mathrm{PTH}(>42 \mathrm{pmol} / \mathrm{L})$, high alkaline phosphatase activity, and volume and weight of the parathyroid adenoma removed ( $>2 \mathrm{~g}$ ) [4]. Supplementing vitamin D deficiency reduces the risk of developing HBS [5]. In the presented clinical case, thanks to early supplementation with calcium, vitamin $\mathrm{D}$, and magnesium preparations, no symptoms of hypocalcaemia were observed. In conclusion, this case report presents a classic example of hypercalcaemia crisis. Hypercalcaemic crisis is more often observed with ectopic localization of parathyroid adenoma. Early postoperative calcium and alphacalcidol substitution prevents the development of hungry bone syndrome.

\section{References}

1. LoPinto M, Rubio GA, Khan ZF, et al. Location of abnormal parathyroid glands: lessons from 810 parathyroidectomies. J Surg Res. 2017; 207: 22-26, doi: 10.1016/j.jss.2016.08.045, indexed in Pubmed: 27979480.

2. Buege MJ, Do B, Lee HC, et al. Corrected calcium versus ionized calcium measurements for identifying hypercalcemia in patients with multiple myeloma. Cancer Treat Res Commun. 2019; 21: 100159, doi: 10.1016/j. ctarc.2019.100159, indexed in Pubmed: 31521048.

3. Saerens J, Velkeniers B, Keyaerts M, et al. Value of [11C]-Methionine PET/CT in Preoperative Localization of Parathyroid Adenomas. Horm Metab Res. 2021; 53(7): 444-452, doi: 10.1055/a-1475-4600, indexed in Pubmed: 34169499.

4. Jakubauskas M, Beisa V, Strupas K. Risk factors of developing the hungry bone syndrome ofter parathyreoidectomy for primary hyperparathyroidism. Acta Med. 2018; 25(1): 45-51.

5. Carsote M, Paduraru DN, Nica AE, et al. Parathyroidectomy: is vitamin $\mathrm{D}$ a player for a good outcome? J Med Life. 2016; 9(4): 348-352, indexed in Pubmed: 27928436. 